\title{
El héroe Cerbero de Pharsalia
}

\author{
Martín M. Vizzotti \\ vizzottim@gmail.com \\ Facultad de Humanidades y Ciencias de la Educación - \\ Universidad Nacional de La Plata, Argentina
}

Recepción: 24 Abril 2018

Aprobación: 17 Mayo 2020

Publicación: 02 Noviembre 2020

Cita sugerida: Vizzotti, M. M. (2020). El héroe Cerbero de Pharsalia. Auster, (25), e063. https://doi.org/10.24215/23468890e063
Resumen: En este trabajo estudiamos las configuraciones internas de los tres personajes "principales" de Pharsalia, César, Catón y Pompeyo. Ciertas características de cada personaje, como la energía demoníaca de César, la virtud inhumana de Catón o la amechania de Pompeyo impiden que cualquiera de ellos pueda ser considerado el "héroe" del en el sentido tradicional; lo mismo sucede con ciertas representaciones y acciones que se suceden en el nivel diegético, donde el carácter sanguinario de César, la boda fúnebre de Catón o las dudas constantes de Pompeyo ofrecen argumentos para cuestionar las bases éticas y morales de cada uno. Estas inadecuaciones en la estructura profunda de cada personaje se complementan unas a otras, subvirtiendo la representación heroica tradicional dentro del poema y conformando un nuevo tipo de héroe: un monstruoso héroe de tres cabezas más acorde a la naturaleza de este poema que canta el fin de una era y el nacimiento de otra, nueva y monstruosa.

Palabras clave: Lucano, Héroe, César, Pompeyo, Catón.

Abstract: In this paper we study the internal configuration of the three "main" characters of Pharsalia, Caesar, Cato and Pompey. Caesar's demonic energy, Cato's inhuman virtue or Pompey's amechania forbids them to be considered the true "hero" of the poem and the same happens with certain actions and certain representations in the diegetical level, where Caesar's bloodthirstiness, Cato's funeral wedding or Pompey's doubts all provide ground for moral and ethical ambivalences. These inadequacies in the inner structure of each character complement each other, subverting the representation of a traditional hero within the poem and forming a new kind of hero, a monstrous three headed monster more suited to a poem than sings the end of an era and proclaims the beginning of an atrocious new one.

Keywords: Lucan, Hero, Caesar, Pompey, Cato.

\section{Introducción: Los “hÉroes” De Pharsalia}

La Pharsalia es un poema particularmente complejo, polisémico y polifacético, quizás sea el único poema de la Antigüedad que busca, más allá de los ambages poéticos y las ambigüedades inherentes a toda producción literaria, de manera explícita y programática la coexistencia de significados y significantes opuestos, polémicos y simultáneos como elemento central y constitutivo de su poética. ${ }^{1}$ Esta característica polifacética se ve claramente ya desde el proemio del poema, donde Lucano lleva in extremum la ya innovadora operación virgiliana de desdoblar el objeto poético de su canto: si Homero comienza sus obras 
maestras con los acusativos Ménin y Ándra, cada uno concentrando y aglutinando de manera precisa el material poético y el eje alrededor del cual versará su obra, ${ }^{2}$ e incluso Esquilo inicia su Orestíada con el acusativo Theoús, cuestión central de la trilogía, Virgilio, quien siempre fue un paso más allá (paulo maiora) de las convenciones literarias y de las restricciones de los géneros de la Antigüedad, comienza su Eneida cantando arma virumque (Verg. Aen. I.1) fusionando ambas epopeyas y explicitando su ambicioso proyecto de superar la épica homérica.

Veamos el proemio de Lucano: ${ }^{3}$

Bella per Emathios plus quam ciuilia campos
iusque datum sceleri canimus, populumque potentem
in sua uictrici conuersum uiscera dextra
cognatasque acies, et rupto foedere regni
certatum totis concussi uiribus orbis
in commune nefas, infestisque obuia signis
signa, pares aquilas et pila minantia pilis. I. 1-7.

Guerras más que civiles a través de los campos de Ematia y el derecho entregado al crimen cantamos y el pueblo poderoso que volvió su mano victoriosa contra sus propias entrañas y las formaciones hermanas y, roto el pacto por el poder, el mundo entero sacudido por todas sus fuerzas en una impiedad común, enseñas enDžentadas a enseñas enemigas las águilas pares y los pilos amenazando pilos. ${ }^{4}$

Tenemos nada más y nada menos que ocho objetos directos los cuales, a diferencia de las armas y el hombre virgilianos, no refieren cada uno a cuestiones poéticas diferentes ni hacen referencia a dos posibles estructuras organizadoras de la obra, ${ }^{5}$ sino que todos son parte, o diferentes aspectos, de uno en particular: las Bella plus quam civilia. Cada uno puede ser entendido como una cara particular de un poliedro poético que concentra un aspecto determinado y específico de este conflicto de ribetes cósmicos, ${ }^{6}$ pero que, por sí solos, no dan cuenta de la totalidad del discurso: ${ }^{7}$ cada uno aporta al carácter fragmentario del poema y a su organización como mosaico poético sólo comprensible a través de una operación de lectura que complemente y organice cada cara del entramado poético.

Lo mismo sucede con los personajes centrales o "héroes" de Pharsalia. No tenemos un protagonista claro o siquiera un personaje central que acapare la mayor parte de la acción, sino todo lo contrario: Lucano se ha cuidado muy bien y a conciencia de no otorgar un papel preponderante a ningún personaje de su obra, ni siquiera a los que podríamos considerar como principales: ${ }^{8}$ César y Pompeyo priman en libro I, con una fugaz aunque relevante aparición de Catón en el verso I. 128 mientras que Pompeyo y Catón dominan las acciones del libro II. Luego, la figura de Catón desaparece hasta el libro IX y toman la escena un gran número de personajes secundarios aunque no menores, como Curio, ${ }^{9}$ Vulteyo, Afranio, Petreyo y Esceva entre otros; ${ }^{10}$ cuyas acciones se completan y significan al ser leídas en una estructura de mosaico. César y Pompeyo reaparecen en el libro VII, Pompeyo domina el libro VIII y Catón el libro IX, mientras qué César resurge sobre el final del libro IX y ocupa el corto libro X. ${ }^{11}$ Cabe destacar la aparición de la bruja Ericto en el libro VI, personaje puesto a la altura del triunvirato lucaneano por el prof. W. R. Johnson ${ }^{12}$ pero que, según nuestra perspectiva, no cumple un papel central dentro del complejo sistema de interrelaciones dinámicas que detectamos en el andamiaje discursivo y diegético de César, Catón y Pompeyo, como veremos un poco más adelante.

La dificultad de identificar a uno de estos tres generales como el personaje central del poema ha dominado las lecturas del Pharsalia. ${ }^{13}$ Así, hay quienes preferían la energía y decisión de César por sobre la intransigente 
ética de Catón o quienes forzaban una matriz filosófica a Pompeyo para convertirlo en un proficiens estoico. ${ }^{14}$ Afortunadamente, han surgido estudios posteriores de la obra con actitudes menos apriorísticas y se ha podido ingresar al poema con perspectivas mucho más abarcadoras y enriquecedoras que se adecuan mucho mejor a su naturaleza lábil y polifacética: los trabajos de autores como R. Sklenár (2003), F. Ahl (1976), E. Narducci (1979 \& 2002), Sh. Bartsch (1997), J. Masters (1992) o P. Esposito \& L. Nicastri (1999), inter alia, que nos han ofrecido lecturas a veces encontradas, pero siempre profundas y perspicaces.

\section{LAS INTERRELACIONES ESTRUCTURALES, DIEGÉTICAS Y DISCURSIVAS DE LOS “HÉROES"}

$\mathrm{Al}$ comienzo del poema César y Pompeyo son presentados como ambiciosos generales que conforman un pacto privado y criminal - tu causa malorum/ facta tribus dominis communis, Roma, nec umquam / in turbam missi feralia foedera regni. (I. 84-86; cf. también 1.98 y ss.)-, idea que se verá reforzada en el libro II por las palabras de Bruto (II. 246-25 \& 2.272-288) y Catón (II. 319-323; cf. también IX. 19-30 \& 190 y ss.). ${ }^{15}$ Los tres generales aparecen entremezclados con las causas de la guerra, las cuales Lucano enumerará un poco más adelante (I. 158 y ss); uno se ampara en dioses paradójicos, inexistentes, irracionales o simplemente malvados mientras que la causa del otro tiene como garante a un hombre, el propio Catón: ${ }^{16}$

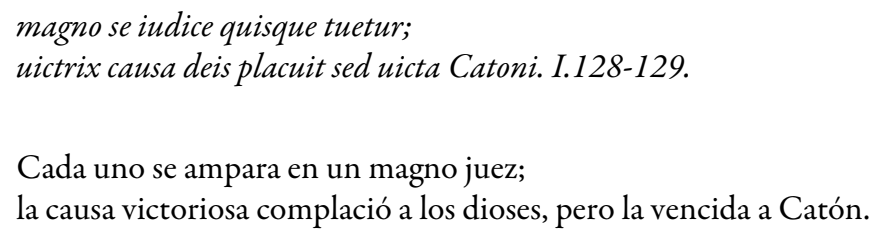

Este dictum es una muestra clara de la genialidad de Lucano y de su capacidad para condensar y comprimir complejas cuestiones literarias y filosóficas en sentencias precisas y subvertirlas radicalmente. ${ }^{17} \mathrm{El}$ narrador del poema muestra una clara ambivalencia al tratar a cada personaje, revelando una esquizofrénica relación con cada uno: en el caso de César, la representación del general como una fuerza demoníaca destinada a asesinar a la República moribunda se contrapone con una cierta admiración difícil de disimular. ${ }^{18}$

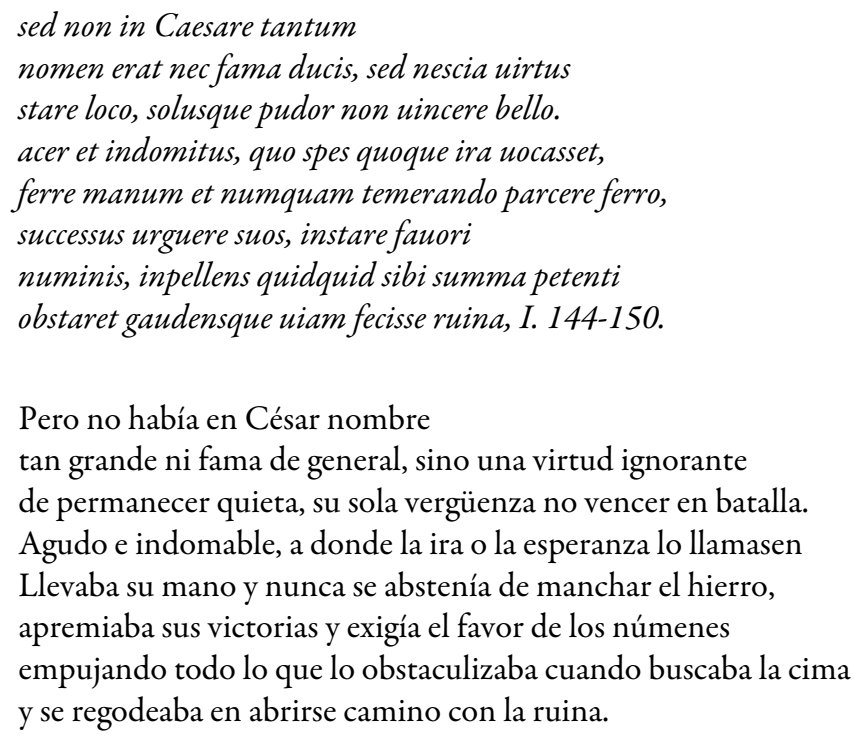

Los versos 147-148 y 150 pueden pensarse como una descripción de la personalidad poética del propio autor, que tiene más en común, como poeta, con César que con el rígido, reaccionario y conservador optimate 
Catón. ${ }^{19}$ En lo que respecta al andamiaje y a la construcción interna del personaje, destaca el oxímoron nescia virtus que, como ya destacamos, subvierte radicalmente el paradigma estoico, pues para estos la virtud jamás puede ser ignorante. ${ }^{20}$ Esta operación de disolución y subversión de los elementos centrales y constitutivos del vir Romanus, la pietas, la virtus, la fides e incluso el amor es pervasiva en toda la Pharsalia, ${ }^{21}$ y uno de los elementos centrales de esta operación literaria está muy presente, como veremos un poco más adelante, en la construcción del personaje de Catón.

Es, sin embargo, en las palabras que César dirige a la imagen temblorosa de la Patria (1.186) donde se aglutinan y concentran por primera vez en el texto elementos comunes a los tres personajes en esta operación de imbricación discursiva que estamos rastreando:

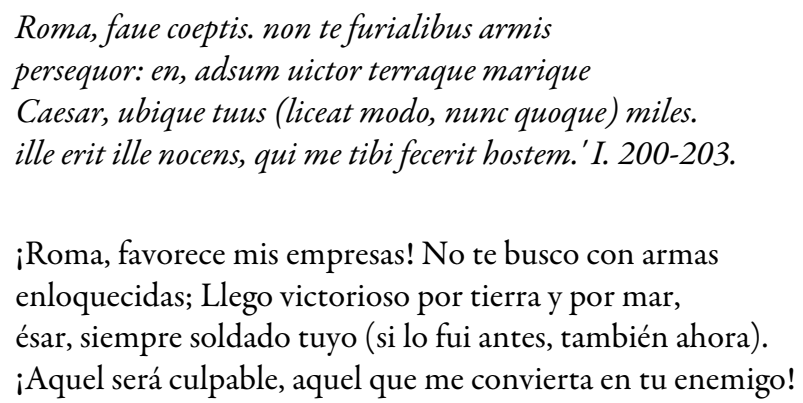

Hay en esta pequeña elocución una gran cantidad de elementos operativos dentro de la construcción de los tres generales: Pompeyo resuena en el verso 200, pues proferirá las mismas palabras que César cuando, en el nadir de su romanidad, ${ }^{22}$ intente forjar una alianza con los Parthos (VIII. 322-327); César aparece de manera explícita en los versos 201-202 23 y Catón, por su parte, dirá conceptos muy similares a los expuestos por César en el verso 203 cuando acuse a los propios dioses de hacerlo incluso a él culpable. Luego del discurso de Bruto, en el cual, como ya dijimos, se destacan las similitudes entra los generales enemigos y sus ambiciones de poder y se eleva nuevamente a Catón como único garante de la legitimidad en este conflicto (II. 246-284), ${ }^{24}$ el general pronuncia las siguientes palabras: ${ }^{25}$

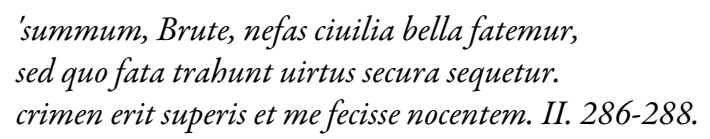

Reconocemos, Bruto, que la guerra civil es la más grande impiedad,

Pero a donde los hados la arrastren, la virtud los seguirá segura.

Será el crimen de los dioses, el hacerme también a mí culpable.

No resuena aquí la figura de Pompeyo, con quien Catón se construirá más por oposición que por yuxtaposición, pero si es posible ver cómo ambos generales se posicionan de manera idéntica, declarando culpables a sus enemigos o adversarios de manera explícita. En este discurso también se ve confutado, en el verso 287 uno de los pilares racionalistas del estoicismo, ${ }^{26}$ pues la aceptación racional y meditada del hado, de acuerdo a la virtus secura del sabio, no puede llevar jamás a éste hacia el crimen absoluto. ${ }^{27}$ Es más, Lucano logra, con solo intercambiar un verbo particular y específico de la terminología estoica, agregar radicalidad y expresividad discursiva a esta operación de subversión del paradigma filosófico: al utilizar trabunt en vez del ducunt Lucano conturba la visión estoica desde sus bases más profundas y radicales, tal como están expresadas en la obra del máximo exponente del estoicismo de su época, es decir, la de su propio tío Séneca. ${ }^{28}$ En su epístola CVII, 11 dice Séneca "Ducunt volentem fata, nolentem trabunt", concepto que ya antes había expresado en su diálogo De providentia 5.4, donde afirma "boni uiri laborant, inpendunt, inpenduntur, et 
uolentes quidem; non trabuntur a fortuna, sequuntur illam et aequant gradus; si scissent, antecessissent." La paradoja de un vir bonus arrastrado por el hado y siguiendo el ideal de la virtus directo hacia el crimen más alto confuta el paradigma estoico en su totalidad. ${ }^{29}$

Esta disolución del entramado filosófico y del propio universo se extiende, vía sympátheia tôn holôn, ${ }^{30}$ a todos los ideales de la República:

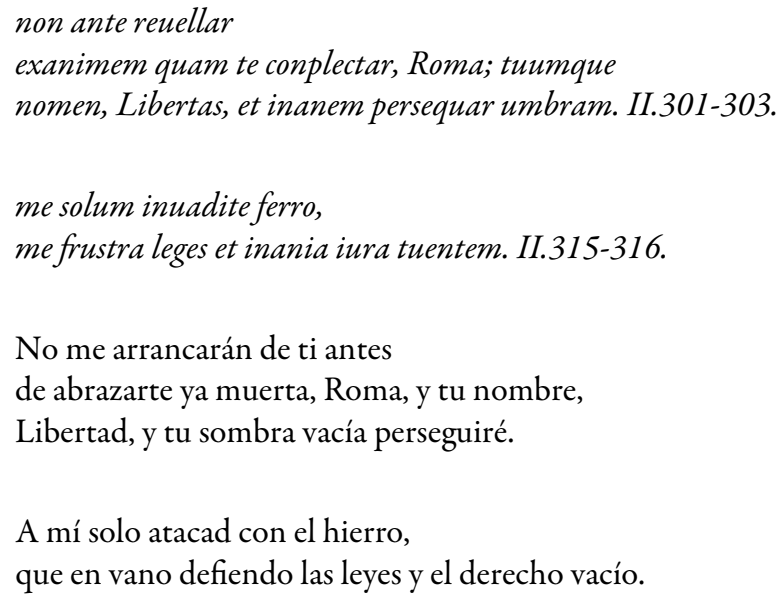

Catón, el parens uerus patriae (IX. 601), constantemente se referirá a la libertad, a Roma y a sus leyes con el adjetivo inanis,e, y la propia Marcia rogará a su futuro esposo que le otorgue el tantum nomen inanel coniubii (II. 342-343). La ceremonia nupcial entre Catón y Marcia es otro claro ejemplo de la inhumanidad inherente a la virtud extrema y desmesurada de este último varón romano. Más funeral de la República muerta y entierro de los inadecuados mores maiorum, la ceremonia se caracteriza por ser yerma y lúgubre: Marcia se presenta visceribus lassis partusque exhausta pidiendo los antiguos foedera inlibata (II. 338-344) vistiendo aún los atuendos fúnebres, lo cual está en concordancia con el aspecto de su futuro marido, quien ya está de luto por la República (II.365-376). ${ }^{31}$ En definitiva la boda es una alegoría donde se muestran la inhumanidad de la virtud catoniana y el compromiso del último varón recto y tenaz en su propósito, encarnación de unos valores inadecuados en este nuevo orden mundial que se está gestando. ${ }^{32}$ Los elementos constitutivos de Roma y los ideales republicanos se han vuelto nombres inanes y vaciados de contenido: el único camino para los últimos romanos es una huida hacía los límites del mundo conocido, a través de las arenas ardientes e infestadas de serpientes de Libia: ${ }^{33}$

o quibus una salus placuit mea castra secutis indomita ceruice mori, conponite mentes ad magnum uirtutis opus summosque labores. uadimus in campos steriles exustaque mundi, qua nimius Titan et rarae in fontibus undae, siccaque letiferis squalent serpentibus arua. durum iter ad leges patriaeque ruentis amorem. IX. 379-385.

serpens, sitis, ardor harenae dulcia uirtuti; gaudet patientia duris; laetius est, quotiens magno sibi constat, honestum. sola potest Libye turba praestare malorum ut deceat fugisse uiros.' sic ille pauentis incendit uirtute animos et amore laborum, inreducemque uiam deserto limite carpit; et sacrum paruo nomen clausura sepulchro 
inuasit Libye securi fata Catonis. IX. 402-410.

O vosotros, a quienes, siguendo mis campamentos, complació como única salvación morir con el cuello indómito, preparad las mentes para el magno trabajo de la virtud y los más altos esfuerzos.

Nos adentramos en los campos estériles y calcinados del mundo donde el Sol es excesivo y rara el agua en las fuentes, y los campos áridos están cubiertos de mortíferas serpientes. El duro camino a las leyes y al amor por la patria que se desmorona.

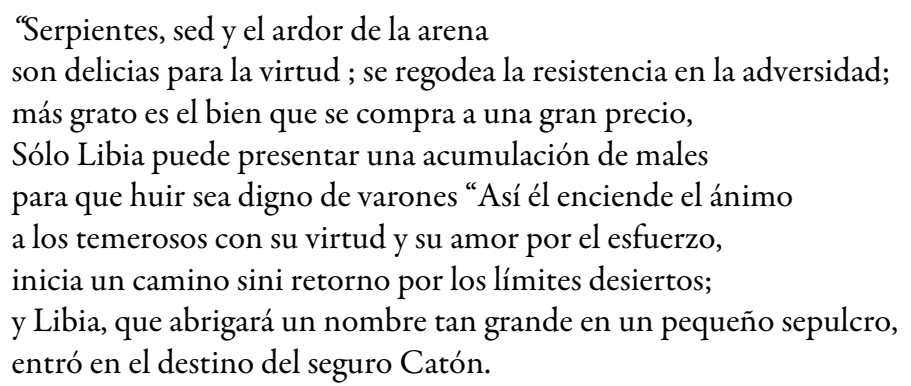

Vale la pena destacar el interesantísimo desplazamiento semántico que se produce con el adjetivo securus, a, um: si en el libro II la virtus era secura, ahora es Catón quien recibe esa distinción; este desplazamiento se ve reforzado por la inversión entre sujeto y objeto, procedimiento muy caro a Lucano a lo largo de todo el poema, ${ }^{34}$ pues, de la misma manera que en el verso VI.31 1 Lucano se lamenta de que luego de la guerra civil la vida carecerá de Catón, ${ }^{35}$ No será Catón quien entre en los destinos de Libia, sino viceversa. En este universo disoluto, la virtus ha arrastrado al sabio al crimen y ha arrojado a los últimos romanos a las antípodas de Roma (IX. 871 y ss.) donde las últimas e impotentes manifestaciones de la virtud tienen lugar. ${ }^{36}$

César y Catón, entonces, son figuras supra-humanas, más símbolos que personajes históricos: ${ }^{37}$ César encarna una fuerza cósmica que se revela como la manifestación en el plano diegético de un proceso histórico inexorable; ${ }^{38}$ Catón, por su parte, encarna los inadecuados ideales Republicanos dentro de un universo en disolución, cósmica, social e individual, ${ }^{39}$ pero, de manera no diferente a César, revela una profunda inhumanidad que pone de manifiesto, del mismo modo que lo hace Séneca en sus tragedias, el costado más oscuro y paradójico de la doctrina estoica. ${ }^{40}$ Tenemos dos personajes en apariencia opuestos y antagónicos, pero cuyas estructuras profundas, tanto en el plano semántico como en el diegético, resultan extremadamente cercanas: los extremos, en definitiva, se tocan y no resultan tan diferentes después de todo. Pompeyo funciona como un puente entre las figuras de estos dos generales, actuando, como ya dijimos como el fiel de una balanza en cuyos extremos están estos dos avatares supra-humanos. ${ }^{41}$

\section{El color humano de la figura de Pompeyo}

Hay, en el Pompeyo de Lucano, una profunda humanidad trágica: ${ }^{42}$ único personaje en la obra que sueña y llora y que se justifica vanamente cuando no logra estar a la altura de los acontecimientos, ${ }^{43}$ es un personaje demasiado humano situado en el bando equivocado dentro de un proceso histórico inexorable. ${ }^{44}$ Si César es el avatar de la historia y Catón el de los ideales de una república ideal, ${ }^{45}$ Pompeyo, en cierta medida, representa el estado actual y real de Roma a mediados del siglo I a.C. y quizás también el del I d.C, con su demagogia banal y su magnificencia decadente, pero que resulta, al mismo tiempo un personaje amable y querible. ${ }^{46}$ Descrito como una vieja y venerable encina (I. 136 y ss), Pompeyo es sólo una magna nominis umbra (I. 135) que comprende el tercer paradigma imperfecto de heroicidad y resulta, quizás, el 
más complejo en sus polivalente y multifacética representación. ${ }^{47}$ Los héroes post homéricos poseen, en mayor o menor medida, ribetes y colores trágicos y Pompeyo es, dentro de poema tan impar como Pharsalia, el personaje que más cercano a estas figuras tradicionales pero carece de la grandeza y la magnanimidad de otros héroes épicos como Eneas. ${ }^{48} \mathrm{El}$ general republicano resulta una figura paradójica y contradictoria en su patética magnificencia y es descripto como un victorioso general devenido brazo armado del senado y demagogo banal no sólo por César (I. 310-351) y sino también por el propio narrador (I. 131-143).

Su figura atraviesa por dos procesos simultáneos e inversos: por un lado la figura pública del victorioso general sufre, al igual que el universo, la sociedad y los individuos, un proceso de desintegración progresiva pero, (y es aquí donde quizás podría encontrarse cierto crecimiento personal, que no debe confundirse con un progresivo avance hacia un perfeccionamiento filosófico, como sugieren algunos autores ${ }^{49}$ al mismo tiempo que su honra pública se desvanece, surge magno el hombre como individuo. Al igual que Edipo quien, cuando está en su punto más alto de honra pública siendo rey de Tebas, vive su hora más abyecta y terrible como individuo envuelto en una relación incestuosa, sin embargo logra recuperar su dignidad como ser humano una vez devenido un mendigo ciego y vagabundo. ${ }^{50}$ Pompeyo, básicamente, opera dentro de la estructura narrativa como elemento de contraste barroco, figura que, por oposición y chiaroscuro, ${ }^{51}$ destaca, con su humanidad trágica y su color humano, los rasgos in y supra humanos de César y Catón, actuando como la cabeza central de esta representación monstruosa de heroicidad. ${ }^{52}$

La característica principal de Pompeyo es su amechania ${ }^{53}$ y su tibieza frente a los eventos que debe enfrentar: si Catón se yergue incólume y recto ante cualquier acontecimiento, como el hombre firme y tenaz en su propósito que cantaba Horacio en la Oda 3.3, y César, por su parte, moldea y hasta parece controlar los eventos con su voluntad, Pompeyo en realidad resulta moldeado por ellos. La actitud que cada general toma frente a sus tropas nos da un claro ejemplo de cada una de estas diferentes actitudes. En primer lugar, César, luego de enfrentar un peligroso motín en el libro 5.300 y ss., subyuga y, literalmente, logra someter a los soldados iracundos sólo con su voluntad. Catón, por su parte, muestra la misma decisión que César, aunque en vez de reificar a los hombres intenta elevarlos a su nivel, aunque éste represente un nivel brutal y monstruoso de la virtud (IX. 255 y ss). ${ }^{54}$ Pompeyo, por su parte, cede tímidamente ante los reclamos optimates expuestos por Cicerón (VII. 68-85): ${ }^{55}$

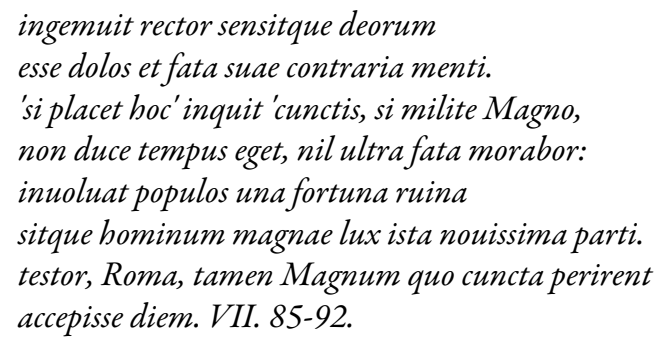

La actitud de Pompeyo es radicalmente diferente a la de César y Catón, la imagen final del general entregándose como un peso inerte a los vientos (VII. 123-127) es una clara muestra de esto. ${ }^{56}$ Cada general recibe, por parte del autor/ narrador, distintos matices que, según la perspectiva axiológica con que se los mire, 
pueden resultar, en principio, positivos o negativos, pero que, debido a las operaciones poéticas extremas a las que son sometidos, resultan siempre problemáticas: si Catón es admirado por su intransigencia ética y César resulta ser (quizás incluso en contra de la voluntad del narrador diegético) por su energía iconoclasta, lo más cercano a Lucano como poeta, ${ }^{57}$ Pompeyo es el personaje que recibe toda la simpatía del narrador, hasta tal punto que ciertas lecturas modernas, particularmente la de la prof. Sh. Bartsch, proclaman al general vencido como el héroe del poema, incluso cuando reconocen que Lucano lo representa de maneras poco favorable. ${ }^{58}$ La derrota taxativa de Pompeyo en la batalla de Pharsalia, incluso contando con superioridad numérica y con una amplia ventaja en el número de jinetes, y su posterior muerte a manos de los corruptos asesores de Ptolomeo en las arenas de Egipto hicieron que se convierta, también, más en una figura simbólica que en un personaje histórico: de este modo, el general silano y optimate que buscaba el clamor popular y que inclinaba las decisiones del senado conduciendo a sus soldados al Foro, ${ }^{59}$ quedó en la historia como el último defensor de la República y del ius Romanus, ${ }^{60}$ aun cuando fue consul sine colega (entre muchas otras "irregularidades" que caracterizaron la carrera política del Pompeyo $)^{61}$ y fue quien acumuló, incluso antes que César y Augusto, numerosos imperia extraordinaria. ${ }^{62}$

Lucano representa a Pompeyo como una general pusilánime que constantemente está intentando retrasar lo inexorable, mientras que César empuja los acontecimientos y Catón los enfrenta y sobrelleva. En su despedida a Cornelia en el libro V (V.727-743), Lucano entremezcla magistralmente las dudas muy humanas del general con el amor a su esposa, representando a Magno dándole la espalda mientras solloza en silencio pues sabe que, terminadas las morae (blandaeque iuuat uentura trabentem/ indulgere morae et tempus subducere fatis (V.732-733)), lo aguardan César y la historia (iam totus adest in proelia Caesar./ cedendum est bellis (V.742-743)). Esta atmósfera trágica cierra también el final del libro V (V.811-815). La tibieza de Pompeyo, luego de ser increpado por Cicerón y forzado a dar batalla, contrasta con la actitud proactiva y decidida de César:

sed mea fata moror, qui uos in tela furentis
uocibus his teneo. ueniam date bella trahenti:
spe trepido; haud umquam uidi tam magna daturos
tam prope me superos; camporum limite paruo
absumus a uotis. ego sum cui Marte peracto
quae populi regesque tenent donare licebit. VII. 294-300.

Pero retraso mis hados; os retengo con estas palabras a vosotros que estáis enloquecidos por las armas, Dad este permiso a quien trae la guerra: tiemblo de esperanza; nunca vi a los dioses tan dispuestos a darme tanto; nos separa de nuestros votos el pequeño límite del campo de batalla. Yo soy quien podrá, terminada las batallas, otorgar lo que poseen los pueblos y los reyes.

El contraste es claro y diáfano, mientras que Pompeyo se entrega a los acontecimientos y se abandona a designios externos, César, temblando de esperanza, destroza cualquier morae y se impone incluso a los dioses.

El contraste con Catón, por su parte, se explicita a través de la tibia devotio que Pompeyo propone, luego de constatar que la Fortuna lo ha abandonado: 
omne nefas uictoris erit.' sic fatur et arma permittit populis frenosque furentibus ira laxat et ut uictus uiolento nauita Coro dat regimen uentis ignauumque arte relicta puppis onus trahitur. VII. 117-127

"Quisiera que la primera lanza de esta guerra funesta hiera mi cabeza, si ha de caer sin sacudir el mundo y sin la ruina de mi partido; Y no será más dichosa la victoria para Magno. Hoy, concluida la matanza, será Pompeyo un nombre odiado por los pueblos, o será Pompeyo un nombre desdichado: Toda la desgracia que traerá la última suerte del mundo, será para el vencido, todo crimen para el vencedor." Así habla y permite las armas a los pueblos y la ira da rienda suelta a los enloquecidos, y, como un marinero vencido por el Coro violento entrega sus velas a los vientos, abandonado su arte, es llevado como un peso muerto en la popa.

Resalta este pasaje por su tibieza, sobre todo si es leído junto a la devotio propuesta por Catón: ${ }^{63}$

deuotum hostiles Decium pressere cateruae: me geminae figant acies, me barbara telis Rheni turba petat, cunctis ego peruius hastis excipiam medius totius uolnera belli. bic redimat sanguis populos, hac caede luatur quidquid Romani meruerunt pendere mores. ad inga cur faciles populi, cur saeua uolentes regna pati pereunt? me solum inuadite ferro, me frustra leges et inania iura tuentem. hic dabit hic pacem ingulus finemque malorum gentibus Hesperiis: post me regnare uolenti non opus est bello. quin publica signa ducemque Pompeium sequimur? nec, si fortuna fauebit, bunc quoque totius sibi ius promittere mundi non bene conpertum est: ideo me milite uincat ne sibi se uicisse putet. II. 308-323.

Los ejércitos enemigos aplastaron a Decio, entregado en sacrificio: que las formaciones hermanas, que la turba bárbara del Rin me ataquen, que yo, en medio de todas las lanzas, muera atravesado por las heridas de toda la guerra.

Que esta sangre redima a los pueblos, que con esta muerte se expíe todo lo que merecieron pagar las costumbres romanas. ¿Por qué mueren los pueblos dispuestos al yugo, por qué mueren queriendo suDžir crueles tiranías? ¡A mí solo atacadme con el hierro, a mí que en vano cuido las leyes y las leyes vacías! Este cuello, éste entregará la paz y el fin de las desgracias a la gente de Italia: luego de mí, no habrá necesidad de hacer la guerra para quien desee reinar. ¿Por qué seguimos las banderas republicanas y a Pompeyo como general? Está bien claro que, si la Fortuna lo favorece, el también se promete el derecho sobre el mundo entero: por lo tanto que venza conmigo como soldado, para que no piense que venció para sí mismo.

Por otro lado, la representación de Pompeyo como un timonel vencido por los vientos opera en paralelo con el famoso pasaje de César y la tempestad del libro V (V. 499 y ss; esp. 575 y ss): ${ }^{64}$ 


\author{
dum se desse deis ac non sibi numina credit, \\ sponte per incautas audet temptare tenebras \\ quod iussi timuere fretum, temeraria prono \\ expertus cessisse deo, fluctusque uerendos \\ classibus exigua sperat superare carina. V. 499-504
}

Mientras cree que el le falla a los dioses y no los dioses a él,
voluntariamente se atreve a desafiar a través de las tinieblas incautas
el mar que temieron sus subordinados, sabedor de que la temeridad
ha alcanzado el éxito, cuando los dioses son propicios,
y espera superar las olas temidas por una flota
en una pequeña barcaza.

César, plantado en la proa de una pequeña barcaza desafía a los elementos y a los dioses y no es casual que él se refiera a sí mismo como el onus que defenderá su nave de la tempestad: hanc Caesare pressam/ a fluctu defendet onus. (V.585-586). Los elementos en común constitutivos de cada personaje operan por clara oposición, Pompeyo es un peso muerto e inerte que retrasa lo inevitable mientras que César es la carga que garantiza la ruptura de las demoras y la seguridad de la nave (V.577-587). De igual modo, basta ver cuán distintas son, en tono y en sinceridad las devotiones de Pompeyo y Catón (interconectados también al resonar el verbo trabitur en VII.127).

\section{Pompeyo Magno: Cenit y Nadir}

El libro VII nos muestra a Pompeyo en toda su futilidad y amechania como general y como individuo; el libro 8, por su parte, nos muestra el nadir de su romanidad, pero también el cenit de su individualidad. Aunque en el libro VII su huida había sido narrada, cuando menos, de manera digna, el comienzo del libro VIII sorprende mostrándolo temeroso y asustado, espantándose de las ramas movidas por el viento o por la llegada de sus soldados (VIII. 1 y ss.). ${ }^{65}$ Creemos que este flagrante desajuste es buscado concientemente por Lucano para resaltar y comprimir dentro de un sólo libro las trayectorias opuestas del general, que ya mencionamos anteriormente: comenzando por su derrota absoluta en los campos de Pharsalia y su vergonzosa huida hasta el encuentro con Cornelia tenemos a un Pompeyo derrotado (VIII. 76-85), ${ }^{66}$ el cual, mientras su figura pública es desintegrada por la fuerza de la historia, junto con Roma y con el mundo entero (tal como le pasará también a su propio cuerpo, VIII. 663 y ss.), surge magno el individuo luego de perderlo todo: : uiuit post proelia Magnus/ sed fortuna perit. quod defles, illud amasti (VIII.84-85). Aparece nuevamente el juego semántico de la palabra Magnus, que oscila entre las funciones sintácticas de sujeto y predicativo subjetivo, logrando Lucano una ironía trágica exquisita, ya que el propio Pompeyo ignora que, si bien está casi terminado su proceso de desintegración pública, ha comenzado su proceso de redención humana y de reivindicación personal. Si bien

algunos autores han propuesto a Pompeyo como un proficiens, ${ }^{67}$ cabe destacar que no coincidimos en que el crecimiento del general derrotado sea en relación al paradigma estoico, sino que es de orden personal y profundamente humano. Pompeyo llora su derrota al mismo tiempo que lo hace su esposa, y sus palabras parecen estar dirigidas más así sí mismo que hacia ella - quod defles, illud amasti, pues no concibe ser amado si no es admirado. ${ }^{68}$

Sin embargo, para llegar a su cenit como individuo, Pompeyo debe alcanzar el nadir de la romanidad en su vana propuesta de alianza con el rey parto (VIII. 217-238). Aflora en este discurso los peores aspectos del personaje, su banalidad y su vanidad y la particular manera de justificarse. Repasemos brevemente la historia diplomática entre Roma y Partia: Sila fue el primer general romano en realizar un foedus amicitiae en el año 96, pacto que fue ratificado por el Senado al año siguiente. ${ }^{69}$ Luego Lucullus intenta, en el marco de su campaña sobre el Ponto durante los años 69-68 establecer una nueva alianza, pero este intento se ve 
truncado por diversas intrigas políticas, luego el Senado, receloso de Lucullus, entrega a Pompeyo la campaña contra Mithridates prácticamente ya resuelta por Lucullus en el año 66, adquiriendo otro imperium gracias a la lex Manilia y renueva oficialmente el tratado de amicitiae con Phraates. ${ }^{70}$ Luego de empujar y cercar a Mithridates a las costas del norte del Mar Negro, deja el final de la campaña a sus lugartenientes y dirige algunas expediciones punitivas, à la César, ${ }^{71}$ más allá del Cáucaso hasta las costas del Mar Caspio, pero cuidándose muy bien de no penetrar en territorio Parto. ${ }^{72}$

Por lo tanto, Pompeyo, en su declamación, no falta necesariamente a la verdad, pero sí da una versión exagerada y propagandística de los hechos (VIII. 229-232). Sin embargo, esta versión indulgente y banal de sus res gestae se ve opacada por lo que podríamos considerar casi un acto fallido cuando reconoce haber operado políticamente luego del desastre de Carrhas, pero peor aún resulta su frase final, la cual consideramos que lo muestra en el nadir de su romanidad: Pompeio uincite, Parthi,/ uinci Roma uolet. Un poco más adelante, Lucano pondrá en boca de Pompeyo, luego de haber explicitado su intención de pactar con el reino oriental, las siguientes palabras: Roma, fave coeptis (VIII. 322 \& 1.200): pero si César, al menos, proclama su intención de liberar Roma de sus amos, detrabimus dominos urbi seruire paratae (I. 351), Pompeyo propone, básicamente, rendir Roma.

Luego de ser refutado por Lentulo (VIII.331 y ss.) el general se reivindica a sí mismo gracias a la dignidad con que enfrenta su final en las costas de Faros: es, a pesar de todo, un vir Romanus capaz de marchar a la muerte con versos de Sófocles en los labios (VIII. 575-582). ${ }^{73}$ Pompeyo, fiel a sí mismo, enfrenta la muerta con una curiosa mezcla de dignidad y banalidad (VIII. 610-630), ${ }^{74}$ sólo cuando lo ha perdido todo se reclama y reivindica para sí mismo (VIII. 630-637): ${ }^{75}$

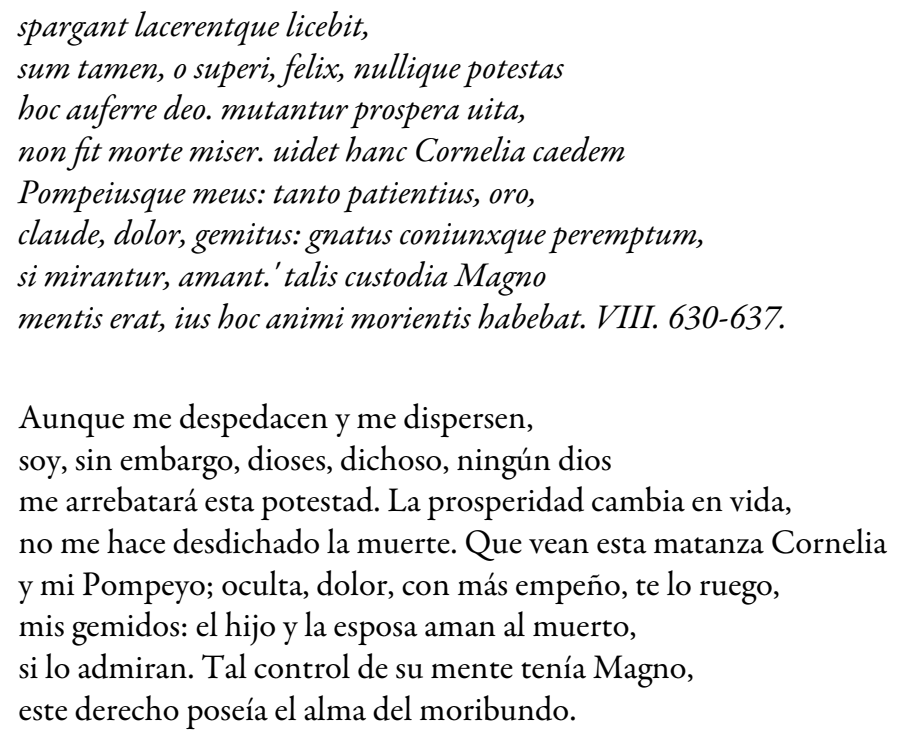

Sus últimas palabras lo muestran en toda su banalidad y humanidad. ${ }^{76}$ Su cuerpo lacerado y decapitado será abandonado en la playa: la añosa y noble encina es ahora un tronco arrojado por el flujo y reflujo de las olas. Sin embargo el general recibirá no un monumental funeral en Roma, sino uno más acorde con su condición personal a esta altura del poema, el humilde y anónimo entierro resulta mucho más honroso y digno y en él se destaca lo patético y lo emotivo. ${ }^{77} \mathrm{El}$ pasaje termina con estos versos:

nautaque ne bustum religato fune moueret inscripsit sacrum semusto stipite nomen: 'bic situs est Magnus'. VIII. 791-793. 
y para que ningún navegante perturbase el sepulcro, luego de desatar sus cabos, escribió el sacro nombre con un leño semiquemado: "Aquí yace Magno".

Cierra nuevamente el pasaje el juego de ambivalencias sintácticas de Magnus (sujeto/ predicativo subjetivo) que ya hemos destacado como una constante a lo largo del poema: "Aquí yace (el) Magno", reza la tumba de este hombre que fuera en vida la encarnación de la última república.

Sigue inmediatamente, al principio del libro IX, el extraño y polémico catasterismo del general, que ha sido considerado ya como la confirmación del Pompeyo proficiens, o como la escena más ridícula de la obra. ${ }^{78} \mathrm{~W}$. R. Johnson acierta, creemos, con su interpretación pero, como suele hacerlo, la lleva in extremum al afirmar que este regalo estoico al menos estoico de los hombres resulta ridículo por naturaleza. Particularmente, creemos que este episodio (9.1-18) presenta ciertas características que no han sido destacadas (al menos hasta donde hemos podido comprobar) por la crítica. En primer lugar, es un catasterismo fallido: la trayectoria del alma de Pompeyo describe una parábola similar a la de un proyectil balístico que roza las esferas ígneas donde habitan los semidei manes (IX. 7-9), pero es claro que no permanece allí, sino que, luego de alcanzar este punto, cae a tierra (los adverbios illic (IX.11) e hinc (IX.15) nos proporcionan esta información), para asentarse en el pecho de Bruto y en la mente de Catón (IX. 17-18). Es cierto que Pompeyo logra una cierta revelación al colmarse de la luz verdadera y trasciende las constricciones mortales (IX. 13-14). Pero desde allí (binc) desciende abandonado estas altas esferas y sobrevuela los campos ematios para convertirse en el símbolo de la república y el vengador de los crímenes contra ella. Acordamos con el prof. Johnson en que Pompeyo no ha mostrado, ni en sus biografías ni en el poema, nada siquiera cercano a esta ignea virtus que templa las almas que habitan las esferas del éter, ${ }^{79}$ de manera similar a las descritas por Cicerón en su Somnium Scipionis, ${ }^{80}$ pero es cierto que su alma se libera de la banalidad que lo caracterizó en vida (IX. 13-14) y puede ser, ahora sí, el símbolo de la bandera republicana. ${ }^{81}$

\section{Conclusiones}

Ninguno de los personajes "centrales" del poema puede ser considerado como el personaje principal o el "héroe" del mismo ya que cada uno, analizado de manera estanca, presenta aspectos ambivalentes inherentes a los presupuestos poéticos que configuran a Pharsalia como un poema dinámico y lábil. Existen, sin embargo, ciertos elementos inherentes a su configuración discursiva en su andamiaje estructural que complementan la representación de cada uno de los generales y que, al ser yuxtapuestos al modo de "legos" discursivos, encastran a la perfección, ya sea por oposición, complementación o afinidad, y conforman de esta manera un héroe monstruoso, un cerbero de tres cabezas que, además, está en consonancia con la desmesura inherente a la poética del poema en su totalidad que confuta los modelos heroicos tradicionales de una era condenada a desaparecer y más acorde a este nuevo e inexorable proceso histórico.

Estos elementos discursivos muy relevantes, como la imbricación discursiva entre César y Pompeyo a través de la frase Roma, fave coeptis (I. $200 \& 8$. 322) o la subversión del concepto de virtus en la configuración de César y Catón (I. $145 \& 2.287$ ), por ejemplo, ofrecen los elementos de yuxtaposición estructural en la representación de los generales, que se ven reforzadas por las distintas interrelaciones diegéticas que hemos destacado a lo largo de nuestra argumentación. De este modo, Pompeyo opera como el puente y el claroscuro en relación a los otros generales: los modos de enfrentar los acontecimientos de César y Catón revelan las deficiencias del personaje de Pompeyo y reafirman las afinidades internas de estos dos personajes en apariencia antagónicos. Por otro lado, mientras César, con su demoníaca energía y audacia, moldea el curso de los acontecimientos prácticamente sólo con su voluntad, por otro, Catón despliega una intransigencia ética monstruosa en su inhumanidad que lo arrastra hasta los confines del mundo. Pompeyo resulta ser la antítesis de estos dos personajes desmesurados y suprahumanos: Lucano elije representarlo en su faceta más humana, 
un victus navita arrastrado por la fuerza de la historia y llevado como un peso muerto en la nave de un estado a punto de naufragar. Cada general representa un aspecto inadecuado de Roma: Catón es el avatar de un pasado quizás utópico, es el esposo de una República yerma y muerta cuyos ideales has sido desintegrados y vaciados de contenidos; Pompeyo es el amante de la Roma decadente y acomodada del siglo I a.C., venerable y cargada con viejos triunfos y glorias pero cuyas raíces ya no hacen pie en la historia; César es el futuro monstruoso y demoníaco que resultará en la Roma de Nerón y cuyo avance inexorable expulsará del orbe la libertas y la virtus y aplastará la decadente e incapaz de defenderse República de Pompeyo y sus senadores.

En definitiva, sólo a partir de una operación de lectura que confronte y complemente las estructuras discursivas y los desarrollos diegéticos de la representación particular y específica de cada uno de los generales puede lograrse un principio de identidad monstruosa y tripartita que logra balancear los excesos y las falencias de los personajes que por sí solos, y por diseño poético del autor, no logran de otro modo un desarrollo firme y estable.

\section{Notas}

1 Narducci, E., La Provvidenza Crudele. Lucano e la distruzione dei miti augustei, Giardini, 1979, 20 y ss.; Narducci, E., "Deconstructing Lucan. Ovvero le nozze (coi fichi secchi) di Ermete Trimegisto e di Filologia”, en Esposito, P. \& Nicastri, L. (Eds.), Interpretare Lucano. Miscellanea di Studi, Università degli Studi di Salerno, 1999, 38 y ss.; Masters J., Poetry and Civil War in Lucan's Bellum Civile, Cambridge University Press, 1992, 2-4; Bartsch Sh., Ideology in Cold Blood. A Reading of Lucan's Civil War, Harvard University Press, 1997, 3-9 \& 66; Bartsch, Sh., "Lucan” en: Foley, J. (ed.), A Companion to Ancient Epic, Malden, Blackwell, 2005, 495; Johnson W. R., Momentary Monsters. Lucan and his Heroes, Cornell University Press, 1987, 1-5 \& 14 y ss., cf especialmente x: “The Pharsalia is, in Santayana's words, omnimodal: it has no privileged center except for the energetic, bitter, and witty skepticism that devotes itself to demolishing the structures it erects as fast as it erects them."

2 Getty, R., M. Annaei Lucani De Bello Civili. Liber I, Arno Press, 2001, xxv-xxvi; Conte, G., La 'Guerra Civile’ di Lucano. Studi e prove de commento, Quattroventi, 1988,13-14 \& 20-23.

3 Narducci, E., Lucano. Un'epica contro l’impero, 18-22; Conte, G., La 'Guerra Civile’ di Lucano, 11 -12 \& 16-19. Respecto de la antigua polémica sobre la autoría senequiana de las líneas iniciales del poema, ya desestimada, cf. Fantham, E., Lucan, De Bello Civili. Book II, Cambridge University Press, 1992, 7-9 (esp. nota 22).

4 Todas las traducciones son nuestras.

5 Galán, L., Virgilio/ Eneida. Una Introducción Critica, Santiago Arcos ed., 2005, 21-23.

6 Lapidge M., "Lucan's Imagery of Cosmic Dissolution”, Hermes, 107, 1979, 360 y ss.; Sklenár R., The Taste for Nothingness, The University of Michigan Press, 2003, 1-3.

7 Henderson, J., "Lucan/ The Word at War" en: Ramus, Vol. 15, N 1, 1986, passim.

8 Marti, B., "The Meaning of the Pharsalia", The American Journal of Philology, Vol. 66, No 4, 1945, 352-354; Nutting, H., "The Hero of the Pharsalia", The American Journal of Philology, Vol. 53, No 1, 1932, 41.

9 Ahl, F., Lucan. An Introduction, Cornell University Press, 1976, 88-99; Sklenár R., The Taste for Nothingness, 34 y ss.

10 Masters, J., Poetry and Civil War, 208-210; Ahl, F., Lucan. An Introduction, 116 y ss.

11 Ahl, F., Lucan. An Introduction, 150.

12 Johnson W. R., Momentary Monsters, 19 y ss.; Fantham, E. Fantham, E., Lucan, De Bello Civili. Book II, 9-10.

13 Para un panorama abarcativo de las distintas posturas de principios del siglo XX sobre esta cuestión cf. Getty, R., M. Annaei LucaniDe Bello Civili. Liber I, xxiv-xxix; Marti, B., "The Meaning of the Pharsalia”, 352-353.

14 Nutting, H., "The Hero of the Pharsalia", 43; Marti, B., "The Meaning of the Pharsalia", 352 y ss. Contra cf. Seo, M. "Lucan's Cato and the Poetics of Exemplarity", en Asso, P. (ed.), Brill's Companion to Lucan, Brill, 2011, 199.

15 Narducci, E., Lucano. Un'epica contro l'impero, Laterza, 2002, 370-374; Sklenár R., The Taste for Nothingness, 82-84.

16 Johnson W. R., Momentary Monsters, 7-9; Fantham, E. Fantham, E., Lucan, De Bello Civili. Book II, 11; Ahl, F., Lucan. An Introduction, 231-232; Shoaf, R., "Certius exemplar sapientis viri': Rhetorical subversion and subversive Rhetoric in Pharsalia 9", Philological Quarterly, No 57, 1978, 151-152; Sklenár R., The Taste for Nothingness, 8-13; Leigh M., "Neronian Literature: Seneca and Lucan" en: Griffin, M. (ed.), A Companion to Julius Caesar, Cambridge University Press, 2009, 246: "[...] indeed perhaps the greatest proof of the absence or the indifference of the gods is precisely the fact of Caesar's victory (see esp. Luc. VII, 445-59).”

17 Quintiliano, aun a pesar de los reproches que le hace a nuestro autor, no podía dejar de reconocerlo como ardens et concitatus et sententiis clarissimus (QUINT. Inst. X, 1, 90); cf. También Heitland, W., M. Annaeus Lucano. Pharsalia, 
Edited with English Notes by C. E. Haskins, Georg Olms Verlag, 1971, lxv-lxvii \& Morford, M., The Poet Lucan. Studies in Rhetorical Epic, Bloomsbury, 2003, xi.

18 Johnson W. R., Momentary Monsters, 103; Nutting, H., “The Hero of the Pharsalia”, 46; Chen, H., "Caesar Perpetuus? Cyclical Behaviour in Lucan's Caesar Similes", Arethusa, N 47, 2014, 342-343.

19 Otras referencias a César que podrían aplicarse sin inconvenientes al temperamento poético de Lucano se encuentran en Luc. II, 446: concessa pudet ire uia \& II, 557 : nil actum credens cum quid superesset agendum. Sklenár R., The Taste for Nothingness, 101-102; Johnson W. R., Momentary Monsters, 118-123.

20 Edwards, P. (Ed.), The Encyclopedia of Philosophy. 8, Collier-MacMillan, 1967, 19 y ss.; Sansoni G., Enciclopedia Filosofica. IV, G. C. Sansoni editore, 1967, 186 y ss.; Ferrater Mora, J., Diccionario de Filosofía. Tomo II, Ariel Filosófica, 1994,1119 y ss.

21 Sklenár, R. "Nihilistic cosmology and Catonian ethics in Lucan's Bellum Civile”, American Journal of Philology, $\mathrm{N}^{\circ} 120$, 1999, 281-296 Sklenár R., The Taste for Nothingness, 2 y ss., 34-36, 43 y ss. \& 101 y ss.; Lapidge, M., "Lucan’s Imagery of Cosmic Dissolution”, 281-296 \& 334-370.

22 Analizamos este episodio infra.

23 Es interesante destacar la ambigüedad que no por anacrónica deja de ser operativa de adsum ... Caesar, donde resuenan al mismo tiempo el nombre y el título imperial, cf. La Fico Guzzo M., "Replanteo de la épica en el exordio general del Cento Probae: Diálogo intertextual con Lucano, Virgilio y Juvenco”, Quaderni Urbinati di Cultura Classica, Vol. 3, 2012 , 132-133.

24 Seo, M. "Lucan's Cato and the Poetics of Exemplarity", en Asso, P. (ed.), Brill's Companion to Lucan, Brill, 20112, 202-203.

25 antham, E., Fantham, E., Lucan, De Bello Civili. Book II, 132; Narducci, E., Lucano. Un'epica contro l'impero, $384-387$.

26 El mero hecho de que los dioses sean adversarios del sabio es una contradicción irresoluble y paradójica para el estoicismo, pues, si bien pueden ponerlo a prueba, los resultados de estas pruebas nunca serán criminales o contrarios a la Naturaleza. Cf. Sen. Prov. 1. 5-6 \& 2.1-3.1; Sklenár R., The Taste for Nothingness, 5-12. Sobre el personal tratamiento que hace Lucano de las ideas estoicas de su época cf. Narducci, E., Lucano. Un'epica contro l'impero, 43 y ss. \& 163-164.

27 Narducci, E., La Provvidenza Crudele, 70; Sklenár, R., “Nihilistic cosmology and Catonian ethics in Lucan's Bellum Civile”, 288-289; Lapidge M., "Lucan's Imagery of Cosmic Dissolution”, 360-366.

28 Ahl, F., Lucan. An Introduction, 240; Narducci, E., Lucano. Un'epica contro l’impero, 378-388.

29 Sklenár, R., "Nihilistic cosmology and Catonian ethics in Lucan’s Bellum Civile", 290.

30 Bartsch, Sh., “Lucan”, 497; Lapidge M., "Lucan’s Imagery of Cosmic Dissolution”, 370 \& esp. 360-361: “The parallel between the destruction of the state and the cosmic dissolution is drawn explicitly by Lucan in the beginning of Book I. (I, 72-80). In this passage Lucan has consciously and carefully chosen terminology drawn from and informed by Stoic cosmological tradition. Consider conpages which dissolves at ekpýrosis. This word originally meant 'putting together' (con + pingo) and hence 'structure' or 'framework' (of a ship, for example). However, in the first century A.D. the word was used by stoic poets to denote the structure of the universe: Manilius at one point states that the world is restrained or reinforced by aetheriis conpagibus $(2,803)$. Only in Stoic writers is the word conpages used in cosmological contexts; for them, apparently, the word carried connotations of the pneumatic or aetherial bonds which maintain the structure of the universe. The word presumably carries these connotations for Lucan as well." Cf. también Sklenár., R., "Nihilistic cosmology and Catonian ethics in Lucan's Bellum Civile", 282-283.

31 Sklenár R., The Taste for Nothingness, 72-80; Seo, M. "Lucan's Cato and the Poetics of Exemplarity”, 202-203.

32 Salustio recurre también a la imagen de una República yerma, incapaz de dar a luz más varones virtuosos, cuyos últimos exponentes fueron, precisamente, Catón y César en Sal. B. Cat. 53.5: “Sed postquam luxu atque desidia civitas corrupta est, rursus res publica magnitudine sua imperatorum atque magistratuum vitia sustentabat ac, sicuti effeta parentum, multis tempestatibus haud sane quisquam Romae virtute magnus fuit. 6 Sed memoria mea ingenti virtute, divorsis moribus fuere viri duo, M. Cato et C. Caesar."

33 Batinski E., "Cato and the Serpents", Syllecta Classica, 3, 1991, 71-73.; Narducci, E., Lucano. Un'epica contro l'impero, 416-418; Sklenár., R., The Taste for Nothingness, 85-87; Moretti, G., "Catone a Bavio. Via della Virtù, lotta coi mostri e viaggio ai confini del mondo: il modello di Eracle nel IX del Bellum Civile”, en Esposito, P. \& Nicastri, L. (Ed.), Interpretare Lucano. Miscellanea di Studi, Napoli, 1999, 247-249.

34 Bartsch Sh., Ideology in Cold Blood, 66: "The collapse of the autonomous individual amid the wreck of linguistic systems and subject-object relations, the hopelessness of meaningful narrative in a meaningless world, the impossibility of representing the trauma of Romans killing Romans [...] All these are undeniable aspects of Lucan's epic world, and for readers of our times I think they more than undeniable: they ring true with an evocation of particular horrors of the twentieth century."

35 Luc. 6, 311: nec sancto caruisset uita Catone.

36 Batinski E., "Cato and the Serpents”, 73: “The paradoxical nature of the Civil War excludes Cato's participation within this epic world. [...] Cato bows he will not withdraw from the political scene until he embraces the dead Republic 
and follows libertas, which has now become a shadow (2. 297-303). [...] Now that Pompey is dead so is the sham of Republicanism." Cf. también Sklenář, R., "Nihilistic cosmology and Catonian ethics in Lucan’s Bellum Civile”, passim.

37 Marti, B., "The Meaning of the Pharsalia", 358.

38 Chen, H., “Caesar Perpetuus? Cyclical Beheavior in Lucan's Caesar Similes”, 344-346 \& 348-349.

39 Bartsch Sh., Ideology in Cold Blood, 10 y ss.; Salemme, C., "Ruina Mundi e funus nel II livro della Pharsalia", en Esposito, P. \& Nicastri, L. (Eds.), Interpretare Lucano. Miscellanea di Studi, 1999, 159-162.

40 Rosenmeyer, Th., Senecan Drama and Stoic Cosmology, University of California Press, 1989, 43.

41 Johnson W. R., Momentary Monsters, x; Ahl 1976, 159-160.

42 Ahl, F., Lucan. An Introduction, 150 y ss.

43 Pyplacz, J., “Famae Petitor. Lucan's Portrayal of Pompey”, Symbolae Philologorum Graecae et Latinae, Vol. XXIV, No 2, 2014, 104.

44 Ahl, F. Lucan. An Introduction, 157-158.

45 El propio Cicerón se quejaba, en sus cartas a Ático, que Catón parecía vivir en la más en la República de Platón que en las letrinas de Rómulo, Cic. Att. 2.1.8: "nam Catonem nostrum non tu amas plus quam ego; sed tamen ille optimo animo utens et summa fide nocet interdum rei publicae; dicit enim tamquam in Platonis politeiai, non tamquam in Romuli faece sententiam."

46 Pyplacz, J., “Famae Petitor”, 97; Ahl, F., Lucan. An Introduction, 157-158

47 Ahl, F., Lucan. An Introduction, 157-159.

48 Ahl, F., Lucan. An Introduction, 153 \& 156 y ss.; Pyplacz, J., "Famae Petitor”, 99.

49 Ahl, F., Lucan. An Introduction, 169-179; Marti, B., "The Meaning of the Pharsalia", 367.

50 Liapis V., “Oedipus Tyrannus”, en: Ormand, K (ed.), A Companion to Sophocles, Wiley-Blackwell, 2012, 91-93; Beer, J., “Oedipus Tyrannus” en: Markantonatos, A. (ed.), Brill's Companion to Sophocles, Brill, 2012, 105-106 \& 109-110.

51 Segal, Ch., "Senecan Baroque: The Death of Hippolytus in Seneca, Ovid and Euripides", TAPhA 114, 1984,313 \& 320- 321; Tatarkiewicz, W., Historia de la estética I, Akal, 2000, 414; Wölfflin H., Renacimiento y Barroco, Paidos ed., $1968,31 \& 47-49$.

52 Ahl, F., Lucan. An Introduction, 173 y ss.

53 Ahl, F., Lucan. An Introduction, 156-157.

54 Ahl, F., Lucan. An Introduction, 254-259; Sklenár R., The Taste for Nothingness, 85-87; Seo, M. “Lucan's Cato and the Poetics of Exemplarity", 203-204, 206 \& 220-221.

55 Ahl, F., Lucan. An Introduction, 160-162 \& 296-297.

56 La incapacidad, o falta de voluntad, de Pompeyo para enfrentar esta situación contrasta con la otra figura épica que se sabe una situación similar, pero que en ningún momento depone su ímpetu guerrero, la de Turno: ille caput quassans: 'non me tua fervida terrent/ dicta, ferox; di me terrent et Iuppiter hostis. Verg. Aen. 12. 894-895.

57 También Ericto es presentada como un posible alter ego del poeta y/o un aspecto constitutivo de la poética de Lucano en Masters, J., Poetry and Civil War, 205-207 \& 212-213

58 Bartsch Sh., Ideology in Cold Blood, 75-76 \& 78-82; Nutting, H., “The Hero of the Pharsalia”, 48-49

59 Scullard, H., From the Gracchi to Nero. A History of Rome from 133 b.c. to a.d. 68, Routledge, 1982, 121-122; Pyplacz, J., "Famae Petitor", 108.

60 Mebane, J., "Pompey's Head and the Body Politic in Lucan's De Bello Civili", TAPA, № 146, 2016, 204; Masters, J., Poetry and Civil War, 235; Ahl, F. Lucan-An Introduction, 319.

61 Scullard, H., From the Gracchi to Nero, 78-79 \& 85 y ss. El propio Pompeyo, en Pharsalia, sueña, no sin cierta inocencia y candidez, estos pequeños "desvíos" del estado de derecho Romano: Luc. VII. 13 y ss. esp. 13-14: plaudente senatu/sedit adbuc Romanus eques.

62 Boak A., "The Extraordinary Commands from 80 to 48 B.C.: A Study in the Origins of the Principate", The American Historical Review, Vol. 24, N 1, 1918, passim, pero esp. 21-25; Frank, T. "The Background of the Lex Manilia”, Classical Philology, Vol. 9, № 2, 1914, 191-193; Davidson A., "Cicero and the Lex Gabinia", The Classical Review, Vol. 44, N 6, 1930, 224-225; Scullard, H., From the Gracchi to Nero, 95-104.

63 Narducci, E., Lucano. Un'epica contro l'impero, 306 \& 402-403.

64 Morford, M., The Poet Lucan. Studies in Rhetorical Epic, 43-44.

65 Bartsch Sh., Ideology in Cold Blood, 94-95.

66 La Fico Guzzo M., "Replanteo de la épica en el exordio general del Cento Probae", 142.

67 Seo, M. "Lucan's Cato and the Poetics of Exemplarity”, 216.; Marti, B., "The Meaning of the Pharsalia”, 367-373.

68 Ahl, F., Lucan. An Introduction, 174. Cf. el apostrofe del narrador para con el general vencido en Luc. VII,726-727: nunc tibi uera fides quaesiti, Magne, fauoris/ contigit ac fructus: felix se nescit amari.

69 Keaveney A., "Roman Treaties with Parthia circa 95- circa 64 B. C.", The American Journal of Philology, Vol. 102, N ${ }^{\circ} 2,1981,197-198$. 
70 Frank, T. "The Background of the Lex Manilia”, 191-192; Keaveney A., "Roman Treaties with Parthia circa 95- circa 64 B. C.", 196-197.

71 Cae. B. G. 6.

72 Scullard 1982, 102. Es más, sabemos que, ante los avances de Craso, los Partos invocaron los prisca foedera de Pompeyo y Sila. Keaveney A., “Roman Treaties with Parthia circa 95- circa 64 B. C.”, 197-198.

73 Plu. Pomp. 78-79.

74 Pyplacz, J., "Famae Petitor", 110-111.

75 Una visión diferente de este pasaje, donde se asimila la dignidad de Pompeyo en su último instante con una catoniana voluntaria mors, puede hallarse en Seo, M. "Lucan's Cato and the Poetics of Exemplarity”, 213-216.

76 Johnson W. R., Momentary Monsters, 80-81.

77 Mebane, J., "Pompey's Head and the Body Politic in Lucan's De Bello Civili", 201-211.

78 Johnson W. R., Momentary Monsters, 72.

79 Johnson W. R., Momentary Monsters, 70-71.

80 Cic. Som. III, 13 y ss.; Pyplacz, J., "Famae Petitor", 114.

81 Contra cf. Mebane, J., "Pompey's Head and the Body Politic in Lucan's De Bello Civili", 211: "For the narrator, this startling scene of deification represents the culmination of Pompey's transformation into an exemplary figure." 